Ocean Engineering

June 2014, Volume 83 Pages 111-124

http://dx.doi.org/10.1016/j.oceaneng.2014.03.010

http://archimer.ifremer.fr/doc/00186/29677/

(c) 2014 Elsevier Ltd. All rights reserved.

\title{
Synthetic rope responses in the context of load history: Operational performance
}

\author{
Weller S.D. ${ }^{1,{ }^{*}}$, Davies Peter ${ }^{2}$, Vickers A. W. ${ }^{1}$, Johanning L. ${ }^{1}$ \\ ${ }^{1}$ Univ Exeter, Coll Engn Math \& Phys Sci, Exeter, Devon, England. \\ 2 IFREMER, Ctr Bretagne, Marine Struct Lab, Plouzane, France. \\ * Corresponding author : S.D. Weller, Tel.: +44 1326259414 ; email address : S.Weller@exeter.ac.uk
}

\begin{abstract}
:
The utilisation of synthetic mooring ropes for marine renewable energy (MRE) devices is a recent occurrence. Despite current use in the offshore industry, MRE mooring components are typically subjected to highly dynamic loads, necessitating the detailed characterisation of operational and longterm component performance for lifecycle analysis and operations management. To address the uncertainties associated with synthetic mooring components in this application, tension experiments have been conducted on nylon 6 parallel-stranded rope samples at IFREMER, France and the University of Exeter, UK under the consortium MERiFIC (Marine Energy in Far Peripheral and Island Communities). Measurements are reported from harmonic loading tests with different initial bedding-in levels used to investigate the influence of load history on the immediate dynamic properties of the rope. Two irregular load regimes were also applied based on mooring tensions recorded by the South West Mooring Test Facility (SWMTF). Datasets are provided to facilitate the development of rope modelling tools. For the load regimes studied it was found that the operational performance of the rope is strongly influenced by the instantaneous load-strain characteristic. This study provides unique insight into the stiffness and damping properties of synthetic rope in the context of loading regimes relevant to MRE devices.
\end{abstract}




\section{Graphical abstract}

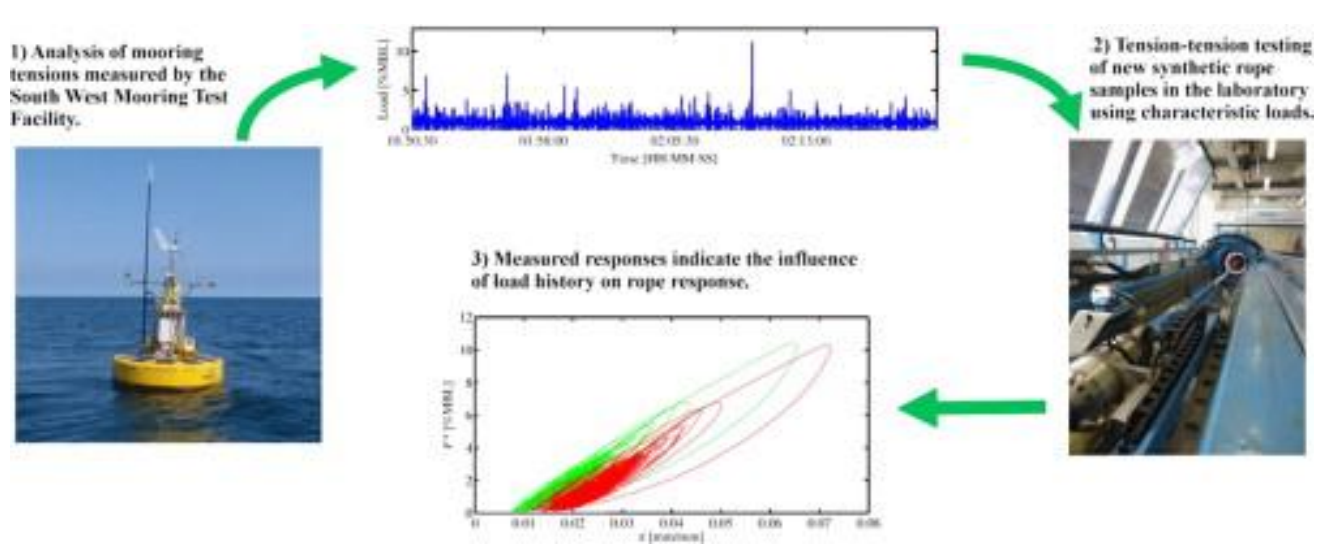

\section{Highlights}

Dynamic tension experiments are reported for three new nylon mooring rope samples. The tests are relevant for offshore equipment, e.g. marine renewable energy devices. Rope axial stiffness and damping are both influenced by instantaneous strain. Instantaneous strain is dependent on the applied load history. To facilitate numerical tool development, supplementary data files are included.

Keywords: Synthetic mooring line, Nylon 6, Parallel-strand rope, Load history, Operational performance

\section{Introduction}

Due to favourable performance characteristics and an inherent ability to reduce peak mooring loads, there has been an increase in the use of synthetic ropes made from materials such as HMPE, polyester, nylon and aramid for the station-keeping offshore equipment over the past two decades [4, 5, 11]. This has led to a number of testing programmes which have primarily been carried out by the oil and gas industry and the development of certification guidelines and standards, such as those produced by Bureau Veritas, the International Standards Organisation, Det Norske Veritas (DNV) and American Bureau of Shipping [1, 3, 7, 13]. Marine renewable energy (MRE) devices are a new field of application requiring the development of robust and economical mooring systems. It is likely that the synthetic materials currently used for existing offshore equipment will feature in the mooring systems of MRE devices [18] and recommendations have been produced to pre-empt the shift from conventional technologies (e.g. The Carbon Trust/DNV [19]). Acting as a point of reference, these guidelines are based on recommendations made for the station-keeping of large offshore equipment and their applicability is questionable for the mooring systems of smaller structures, such as , oating tidal turbines and wave energy converters (WECs) due to differences in mooring system footprint, load regimes, mass distribution, water depth and expected environmental conditions. For example large floating platforms, such as those used for fossil fuel exploration and extraction tend to be located in water depths much greater than WECs (up to 3000 metres for spar platforms). Although the mooring system designs are broadly similar (i.e. catenary or taut-leg geometries), large manned platforms are designed with natural periods which avoid the expected "rst-order wave periods of the area, enabling the platform to remain on station and operate safely. Excitation by longer period, second-order wave forces may be permitted if levels of component fatigue cycling are acceptable. In contrast WECs are designed 
so that the natural periods of one or more modes of motion correlate with the expected wave energy periods in order to maximise the level of energy absorbed for a given location. This can result in highly dynamic device responses which are directly coupled to the response of the mooring system. Given this context signi" cant uncertainties exist about the application of synthetic ropes for MRE devices and it is essential that the operational and long-term performance of mooring components is quantified to enable predictions to be made regarding fatigue life and capacity to withstand extreme loads [14]. The mooring response will be influenced by the physical properties of components within the system (mass, geometry, axial stiffness and damping) $[8,15]$ as well as other loading mechanisms (i.e. viscous drag and added mass). Whilst ultimate strength and axial sti ness have been quantified 
for the loading regimes and rope constructions relevant for large, slow-moving equipment (e.g. $[2,5,6]$ ), material and structural damping are usually not reported. As part of a dedicated component testing program involving the collaboration of L'Institut Français de Recherche pour l'Exploitation de la Mer (IFREMER) and the University of Exeter, as part of a MERiFIC (Marine Energy in Far Peripheral and Island Communities) consortium, the axial stiffness and the damping of several parallel-stranded nylon 6 rope samples are quantified in the context of the operational mooring loads that could be experienced by MRE devices. nylon has been selected due to its compliant properties which may be utilised to reduce peak mooring loads [18]. In this study, harmonic and irregular loading regimes are used to determine the average performance of new rope samples with investigations made on the influence of load history on time-averaged and time-varying performance. In a forthcoming publication rope conditioning will be investigated, with comparisons made between the dry and wet performance of the new rope samples and also the loading behaviour of an aged rope sample utilised on the South West Mooring Test Facility (SWMTF). It is the intention of the present study to provide experimental data that can be used to reduce uncertainties regarding the performance and reliability of nylon mooring ropes, enabling the design of economical mooring systems and facilitating the development of guidelines and standards which are more applicable to MRE devices (e.g. IEC-TS 62600-10 Ed.1.0, [12]).

In the next section the experimental equipment used in this study is outlined. The loading regimes applied to the rope samples are then defined in the context of mooring tension measurements recorded by the South West Mooring Test Facility (SWMTF). The experimental method and analysis techniques adopted are then summarised. In Section 3 results are presented from harmonic load tests involving three new rope samples subjected to different bedding-in levels. To further investigate the effect of load history on sample performance, irregular load tests based on SWMTF mooring tension measurements are presented in Section 4.

\section{Experimental Approach}

\subsection{Equipment used at IFREMER and the University of Exeter}

The synthetic rope studied has a parallel-stranded subrope construction comprising multi-filament nylon 6 fibres, with a minimum break load (MBL) specified by the manufacturer of $466 \mathrm{kN}$. The rope comprises seven subropes surrounded by a non-load bearing jacket, resulting in a crosssectional diameter of $0.044 \mathrm{~m}$ (Figure 1a). Three samples were supplied by the manufacturer pre-spliced with an eyeto-eye distance of approximately $5 \mathrm{~m}$. These ropes form the upper $20 \mathrm{~m}$ of the three catenary mooring lines used on the South West Mooring Test Facility (SWMTF; Figure 1b) which was designed and is operated by the University of Exeter. Located in an average water depth of $30 \mathrm{~m}$ in Falmouth Bay, the lower sections of each mooring line comprise chains and a drag anchor. On the surface is an instrumented buoy which includes a digital GPS unit (10Hz sampling rate) and a multi-axis inertial 'MotionPack' $(20 \mathrm{~Hz}$ sampling rate) as well as a digital compass and sensors to measure temperature, wind velocity, wind direction and salinity. At each mooring limb attachment point, tensions are simultaneously recorded at a sample rate of $20 \mathrm{~Hz}$ by a three-axis load cell in addition to an axial load cell. Current velocities in the water column and surface elevations are recorded at $2 \mathrm{~Hz}$ using a seabed-mounted 4-beam Acoustic Doppler Current Profiler (ADCP) located nearby. In this paper only the tension measurements recorded by the axial load cells are reported. Further details regarding the SWMTF can be found in [16].

The rope samples were subjected to several loading regimes in dry conditions using the 100 Tonne hydraulic test machine at IFREMER. This machine has the capability of testing samples up to $10 \mathrm{~m}$ long in quasi-static and dynamic conditions (e.g. [6], Figure 1c). Extension of the free length of the sample was measured (sample rate: $2 \mathrm{~Hz}$ ) over a distance of $1.1 \mathrm{~m}$ using a draw-wire transducer (ASM Sensors: WS10-375-R1-L10) clamped to the rope, at least $0.25 \mathrm{~m}$ clear of the end terminations and splices. Loads applied to the sample and hydraulic piston displacements were also recorded at a sample rate of $2 \mathrm{~Hz}$. Additional tests to replicate irregular tension time-series measured by the SWMTF and faster harmonic oscillation periods were also conducted using the DMaC (Dynamic Marine Component) test facility at the University of Exeter (Figure 1d). The facility includes a hydraulically powered tailstock for the application of user-defined loads (harmonic and irregular time-series). Although not utilised in this study, a hydraulically powered headstock provides an additional three degrees-of-freedom (roll, pitch and yaw) for applying bending and torsional loads [16]. For this machine, extension of the free length of the sample was measured using a draw-wire transducer (Applied Measurements: WS121000-R1K-L10-SBO-M12) at a rate of 50Hz. Hydraulic piston displacements and applied loads were also recorded at a sample rate of $50 \mathrm{~Hz}$. Due to the occurrence of signal noise, extension measurements were filtered using a lowpass Butterworth filter with a cut-off frequency of $1.5 \mathrm{~Hz}$. A comparison between the IFREMER test machine and the $\mathrm{DMaC}$ test facility is provided in Table 1. 


\begin{tabular}{|c|c|c|c|c|}
\cline { 2 - 5 } \multicolumn{1}{c|}{} & Stroke $\mathbf{( m )}$ & $\begin{array}{c}\text { Static } \\
\text { force } \mathbf{( k N})\end{array}$ & $\begin{array}{c}\text { Specimen } \\
\text { length }(\mathbf{m})\end{array}$ & $\begin{array}{c}\text { Temperature } \\
\text { controlled }\end{array}$ \\
\hline IFREMER & 1.5 & 1000 & 5 & up to $50^{\circ} \mathrm{C}$ \\
\hline DMaC & 1 & 343 & 6 & N $/ \mathrm{A}$ \\
\hline
\end{tabular}

Table 1: Guideline capabilities of the IFREMER and DMaC test machines

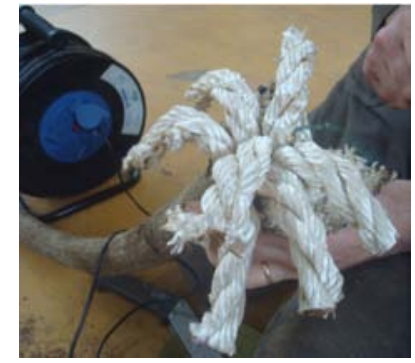

(a)

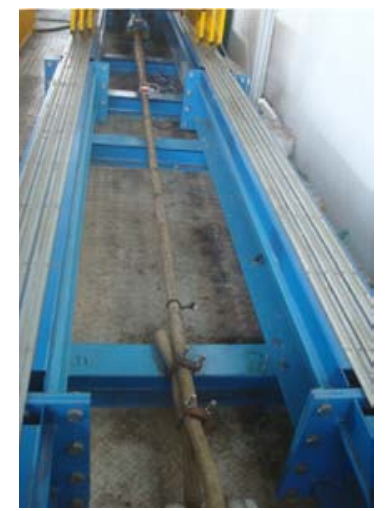

(c)

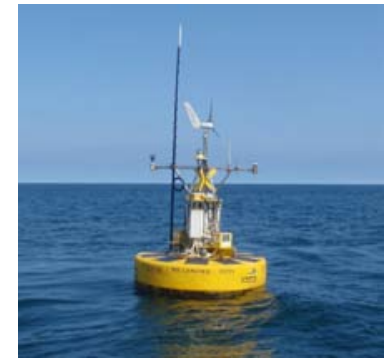

(b)

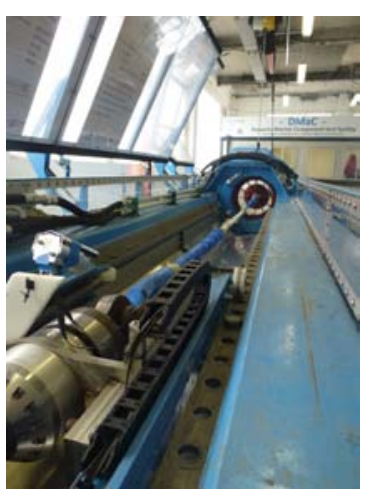

(d)
Figure 1: a) Aged rope with outer jacket removed showing parallelstrand construction. b) SWMTF moored in Falmouth Bay. c) IFREMER 100 Tonne machine and d) DMaC test facility used for rope testing.

\subsection{South West Mooring Test Facility Load Measurements}

In order to replicate loading conditions in the laboratory that are relevant to the mooring systems of buoylike MRE devices, the rope samples were subjected to load regimes defined in the context of mooring line tensions measured by the SWMTF between March 2010 and September 2011 (Figure 2a). During this first deployment a range of load levels and load rates were recorded by the axial load cells, the extremes of which are represented by tension time-series measured in calm (Figure 2c) and mildstorm (Figure $2 \mathrm{~d}$ ) conditions. In calm conditions $\left(H_{s} \approx\right.$ $0.36 \mathrm{~m}, T_{p} \approx 4.1 \mathrm{~s}$, average water depth $32.5-33 \mathrm{~m}$ from ADCP measurements) the average tension for Lines 1-3 was $3.77 \mathrm{kN}$, corresponding to $0.8 \%$ of the rope MBL. During mild-storm conditions $\left(H_{s} \approx 2.67 \mathrm{~m}, T_{p} \approx 7.5 \mathrm{~s}\right.$, average water depth 31.9-32m) much larger loads were measured, with an average tension of $5.97 \mathrm{kN}$. In the plotted timeseries the majority of loads are low amplitude and in the range of $0-4 \%$ of the rope's MBL, in which the stiffness of the rope is highly non-linear [9]. A notable snatch load of $0-52.2 \mathrm{kN}(0-11.2 \% \mathrm{MBL})$ occurred during the mild-storm interval for Line 1 at 02:09:55, providing insight into the survivability of the system during the application of a short duration, high magnitude load. This event does not directly correspond with a large wave peak, instead it is due to the dynamic response of the buoy and the mooring system. Although severe, analysis of the axial mooring loads measured during the first SWMTF deployment indicates that a peak load of this magnitude was an isolated event, with most loads lower than $8 \%$ MBL (Figure 2b; details of the identification method used are outlined in [21]).

\subsection{Rope Testing Procedures}

Standardised rope testing procedures usually include the initial application of bedding-in cycles to enable the rope to be conditioned from its manufactured state to one which is known (e.g. [7, 13]). During bedding-in macroscopic and molecular changes to the structure and fibres occur (i.e. the alignment of molecules in the direction of stress), resulting in non-recoverable, residual strain. To determine the effect of these changes, Samples 2 and 3 were subjected to $10 \mathrm{x}$ cycles of bedding-in using the 100 Tonne machine at IFREMER up to $20 \%$ and $40 \%$ of the MBL respectively, defined as 'BI2' and 'BI3' in Table 2. Sample 1 was treated as a control specimen and no bedding-in cycles were applied (BI1). All three samples were then subjected to a single load/unload cycle followed by harmonic loading (load level A) at three different oscillation periods (50s, $25 \mathrm{~s}$ and $100 \mathrm{~s}$ ) which were intentionally non-monotonic in order of application. Unless otherwise stated, a constant load amplitude was used $(10.7 \mathrm{kN})$. After a short interval of $300 \mathrm{~s}$ during which the load was held constant at $2 \mathrm{kN}$, this process was repeated for four more load levels (B-E) up to a maximum load of $116.5 \mathrm{kN}$ ( $25 \% \mathrm{MBL})$, denoted as 'LS1' in Table 3. After the harmonic loading cycles, the load was then held constant for 1 hour at $3.5 \mathrm{kN}$ and then 9.8 hours at $2 \mathrm{kN}$ (load levels $\mathrm{F}$ and $\mathrm{G}$ ). An example measured load and load rate time-series for Sample 2 subjected to load levels (A-G) is shown in Figure 3a, showing similar load rates to those measured by the SWMTF during calm conditions (Figure 2c). 


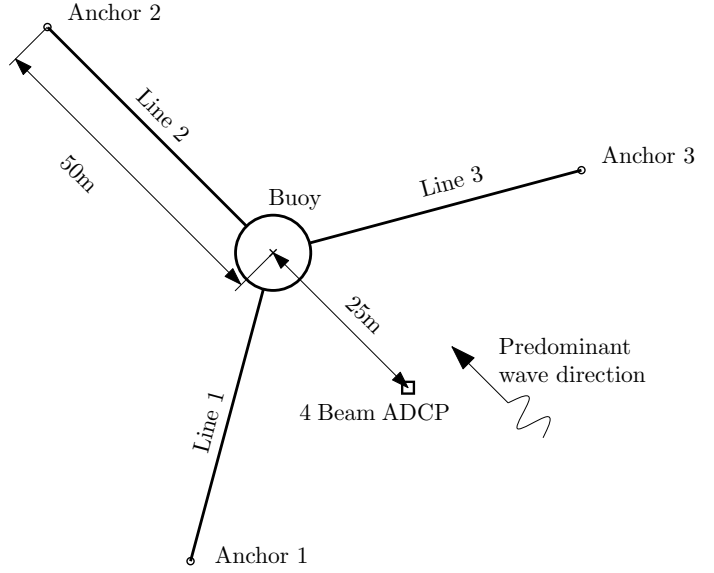

(a)

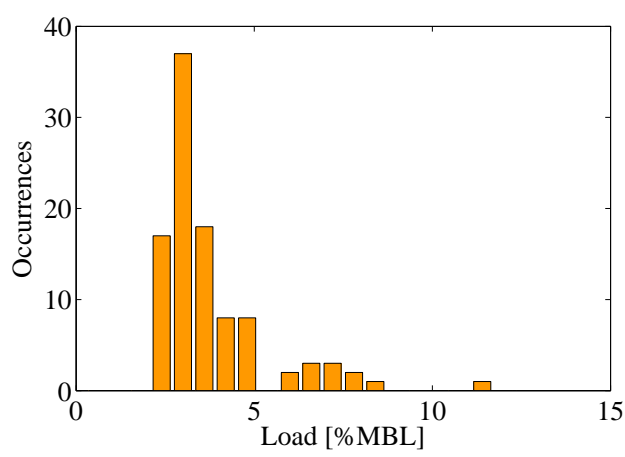

(b)
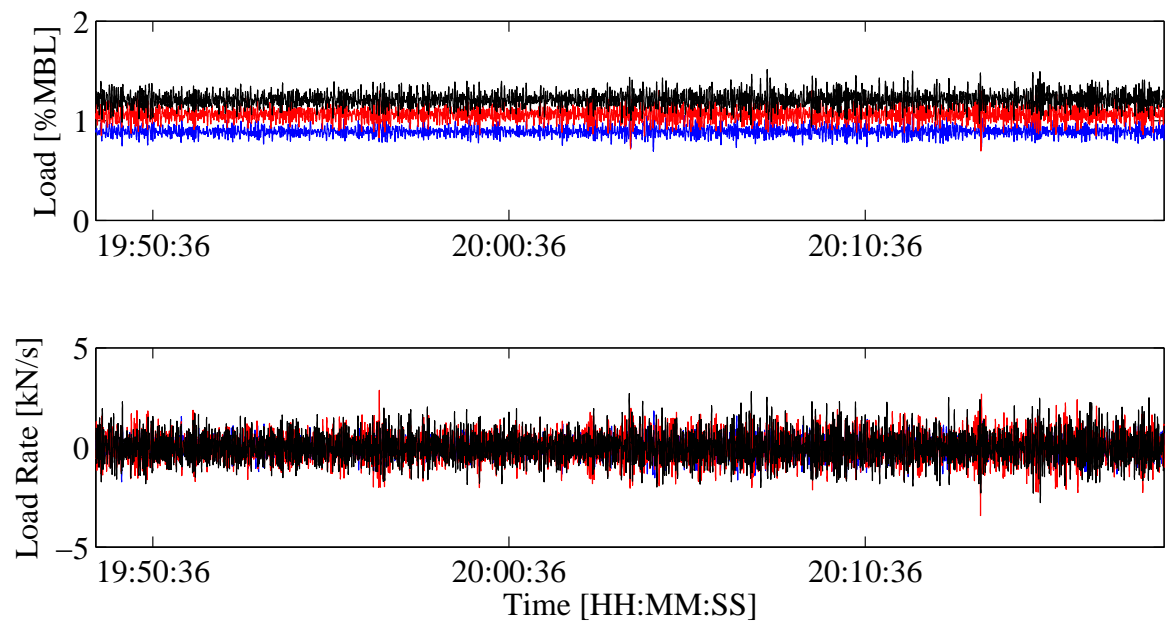

(c)
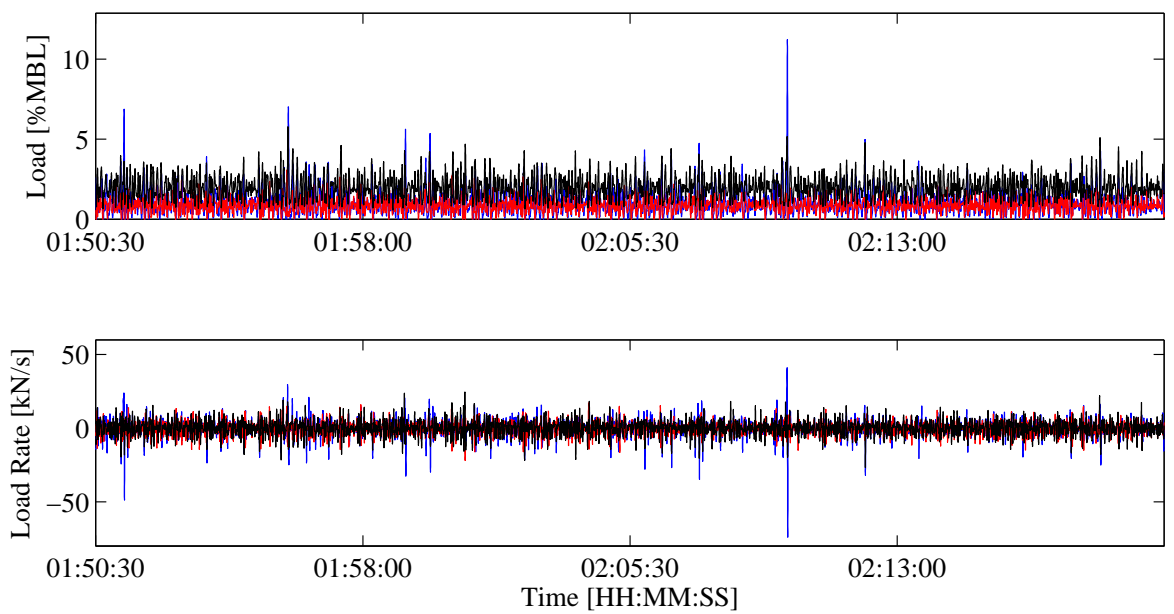

(d)

Figure 2: a) SWMTF mooring arrangement and ADCP location (not to scale). b) Number of occurrences of significant axial mooring loads identified from tension measurements for all three lines recorded during the first deployment [21]. Axial mooring tensions and calculated load rates for Line 1 (blue line), Line 2 (red line) and Line 3 (black line) measured during c) calm (29/09/2010) and d) mild-storm (17/11/2010) conditions. For interpretation of the references to colour in this figure legend, the reader is referred to the online version of the article. 

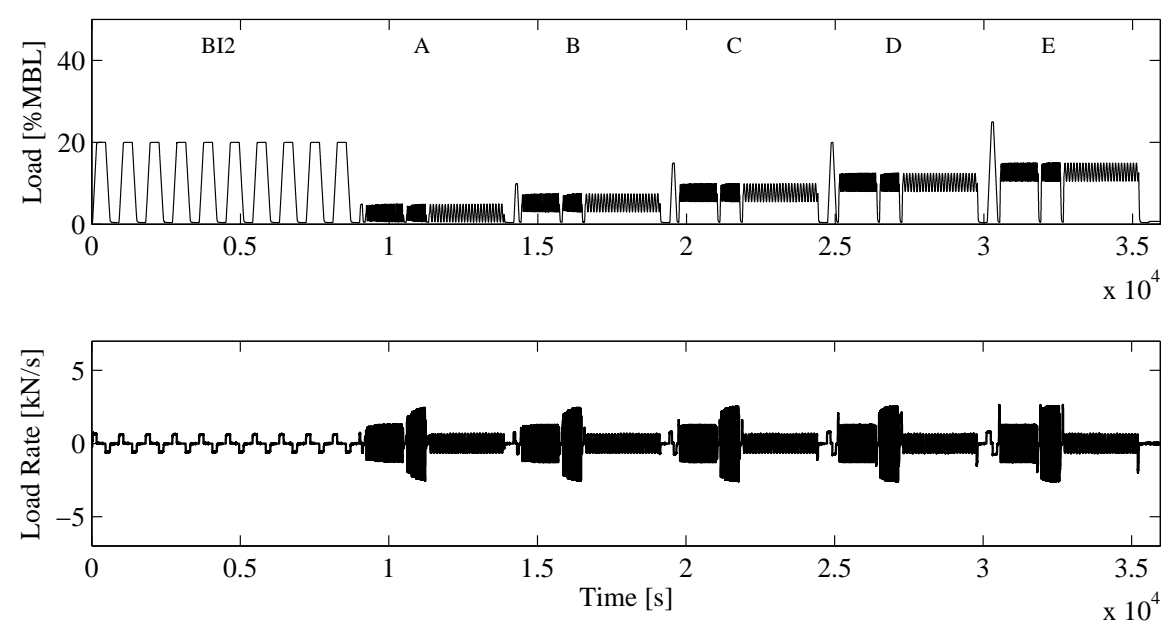

(a)
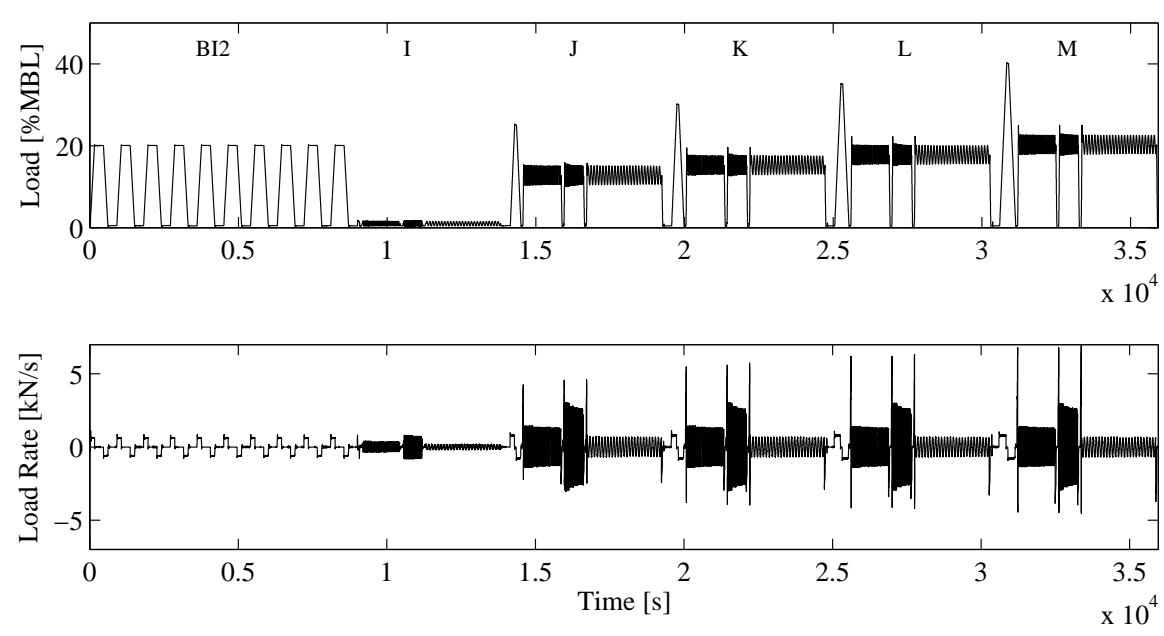

(b)
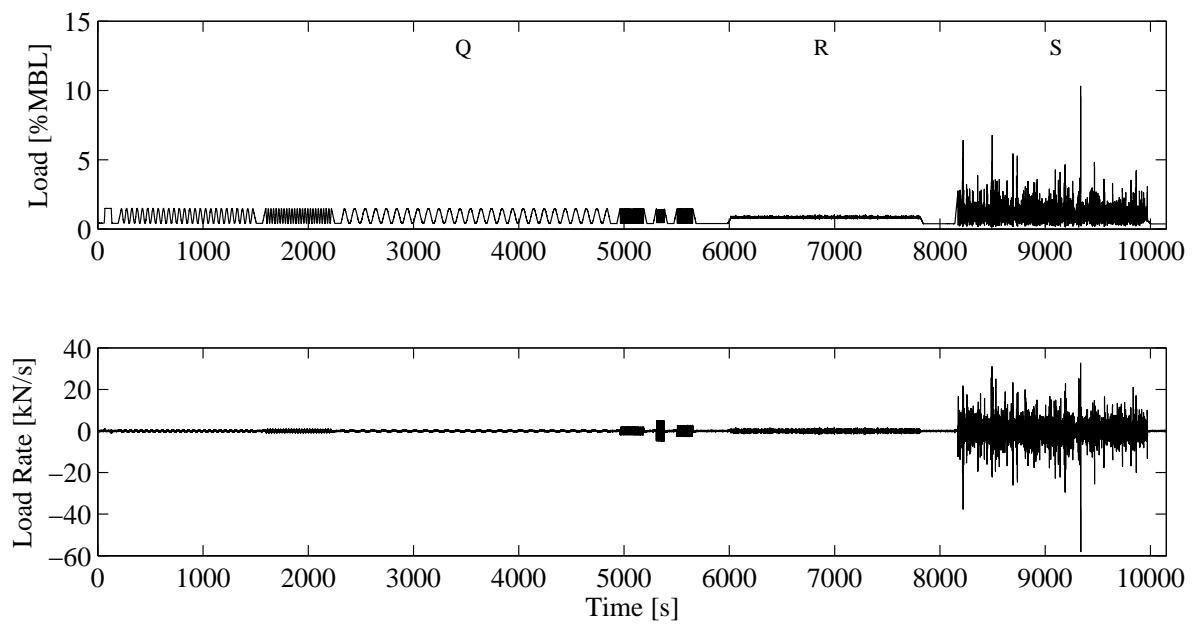

(c)

Figure 3: Measured loads and load rate time-series for the Sample 2 test. Bedding-in cycles (BI2) are shown as well as load levels a) A-E, b) I-M and c) Q-S. In a) and b) only the first 9.9 hours of the load time-series is shown 


\begin{tabular}{|c|c|c|c|c|c|c|c|}
\hline $\begin{array}{c}\text { Bed-in } \\
\text { level }\end{array}$ & Sample & $\begin{array}{l}\text { Number } \\
\text { of cycles }\end{array}$ & $\begin{array}{l}\text { Minimum } \\
\text { load }(k N)\end{array}$ & $\begin{array}{r}\text { Maximum } \\
\text { load }(\mathrm{kN})\end{array}$ & $\begin{array}{c}\text { Ramp } \\
\text { duration (s) }\end{array}$ & $\begin{array}{l}\text { Ramp load } \\
\text { rate }(k N / s)\end{array}$ & $\begin{array}{c}\text { Hold } \\
\text { duration (s) }\end{array}$ \\
\hline BI1 & 1 & None & $\mathrm{N} / \mathrm{A}$ & $\mathrm{N} / \mathrm{A}$ & $\mathrm{N} / \mathrm{A}$ & $\mathrm{N} / \mathrm{A}$ & $\mathrm{N} / \mathrm{A}$ \\
\hline BI2 & 2 & \multirow{2}{*}{10} & & 93.2 & \multirow{2}{*}{150} & 0.61 & \multirow{2}{*}{300} \\
\hline BI3 & 3 & & & 186.4 & & 1.23 & \\
\hline
\end{tabular}

Table 2: Bed-in cycles used on Samples 2 and 3 during load sets LS1-2

\begin{tabular}{|c|c|c|c|c|}
\hline & \multicolumn{3}{|c|}{ Sample } \\
\hline & & $\mathbf{1}$ & 2 & 3 \\
\hline \multirow{3}{*}{ Temperature $\left({ }^{\circ} \mathrm{C}\right)$} & $T_{\max }$ & 21.6 & 22.6 & 23.3 \\
\hline & $T_{\min }$ & 17.0 & 16.1 & 15.0 \\
\hline & $T_{\text {mean }}$ & 19.1 & 19.8 & 18.8 \\
\hline \multicolumn{2}{|c|}{ Humidity (\%) } & 49.2 & 50.9 & 37.0 \\
\hline
\end{tabular}

Table 4: Air temperature ranges and initial humidity levels measured during load set LS2

On a separate occasion the three samples were subjected once again to the same bedding-in levels defined in Table 2 followed by five more load levels up to a maximum load of $186.4 \mathrm{kN}$ (40\% MBL; defined in Table 3 as I-M and illustrated in Figure $3 \mathrm{~b}$ ) followed by steady load levels $\mathrm{O}$ and $\mathrm{P}$. During these tests the load range was extended to include a low load level (I) which has a similar mean load and load amplitude to that measured by the SWMTF during calm conditions. Load level J was identical to load level $\mathrm{E}$ in order to compare the performance of the samples before and after the first load set (LS1) had been applied. For the range of higher loads, the majority of mean loads measured on a cycle-to-cycle basis are close to those specified (with a difference of up to $6.2 \%$ for the first harmonic interval of Sample 1), apart from a slight load overshoot occurring during the first ramp interval of each harmonic interval (e.g. typically around $10 \%$ as shown in Figure 3b). This behaviour, which corresponds to peaks in the load rate time series of up to $6.9 \mathrm{kN} / \mathrm{s}$, was due to the response of the control system during high load rates and could be remedied by the application of alternative proportional-integral-derivative (PID) parameters. Whilst load overshoot would have had some influence on the first few cycles of each harmonic interval, the measured responses suggest that the accumulated strain of the rope by the final cycles was not greatly influenced. As the properties of synthetic materials including nylon can be influenced by fluctuations in the surrounding environment [17], measurements of air temperature were made continuously during testing for load set LS2. The humidity level was also recorded at the start of each test (Table 4).

The samples were then subjected to a third load set ('LS3') using the DMaC test facility at the University of Exeter, comprising the same low load harmonic cycling as load level I with an additional three oscillation periods 9, 6 and 3 s (load level $\mathrm{Q}$ in Table 3 ). The rational for this was to include load conditions (mean, amplitude and rate) which are closer to those experienced in-service by the SWMTF mooring lines or similar MRE equipment. Following a short interval of 300s where the load was held constant at $2 \mathrm{kN}$, the samples were then subjected to a representation of irregular loading (load level $\mathrm{R}$ ) based on SWMTF measurements recorded during calm conditions (as shown in Figure 2c). After this irregular load timeseries, the load was again held constant for $300 \mathrm{~s}$ at $2 \mathrm{kN}$ before a mild-storm load representation was applied (load level S) based on the measurements shown in Figure 2d.

\subsection{Measurement analysis procedure}

The axial stiffness $(E A)$ of the free rope length is calculated as the gradient of a single degree-of-freedom trend line fitted using linear regression to measured load ( $F$; independent variable) and strain ( $\epsilon$; dependent variable) values over each oscillation cycle. Strain is defined as the ratio of instantaneous extension to original length (measured before the start of each test with the sample pretensioned at $2 \mathrm{kN}$ ). Utilising the least squares method, this approach to determine axial stiffness contrasts the commonly used method in which the gradient between maximum and minimum load and strain values is used [10]. Whilst both approaches are likely to give a similar result a steady-state response to harmonic loading, stiffness values determined by the latter method for bedding-in cycles will depend on the duration of ramp and hold intervals, therefore this approach requires the use of standardised hold durations. To illustrate this point, for the 10 bedding-in cycles used on Sample 2 application of a linear trend line yields a closer prediction (quantified by coefficients of determination $R^{2}$ ) than the conventional method reported by Flory et. al in [10] (Table 5). As the intended application of the mooring rope dictates loading mainly in the axial direction, bending stiffness is not considered in this study.

Further to the earlier work carried out by Johanning et al. [15], damping rate, which includes material and structural contributions, is calculated using the energy dissipated over each load-unload cycle $\left(E_{d}\right)$, the angular frequency of the oscillation $(\omega)$ and the amplitude of piston displacement $(X)$ :

$$
B=\frac{E_{d}}{\pi \omega X^{2}}
$$




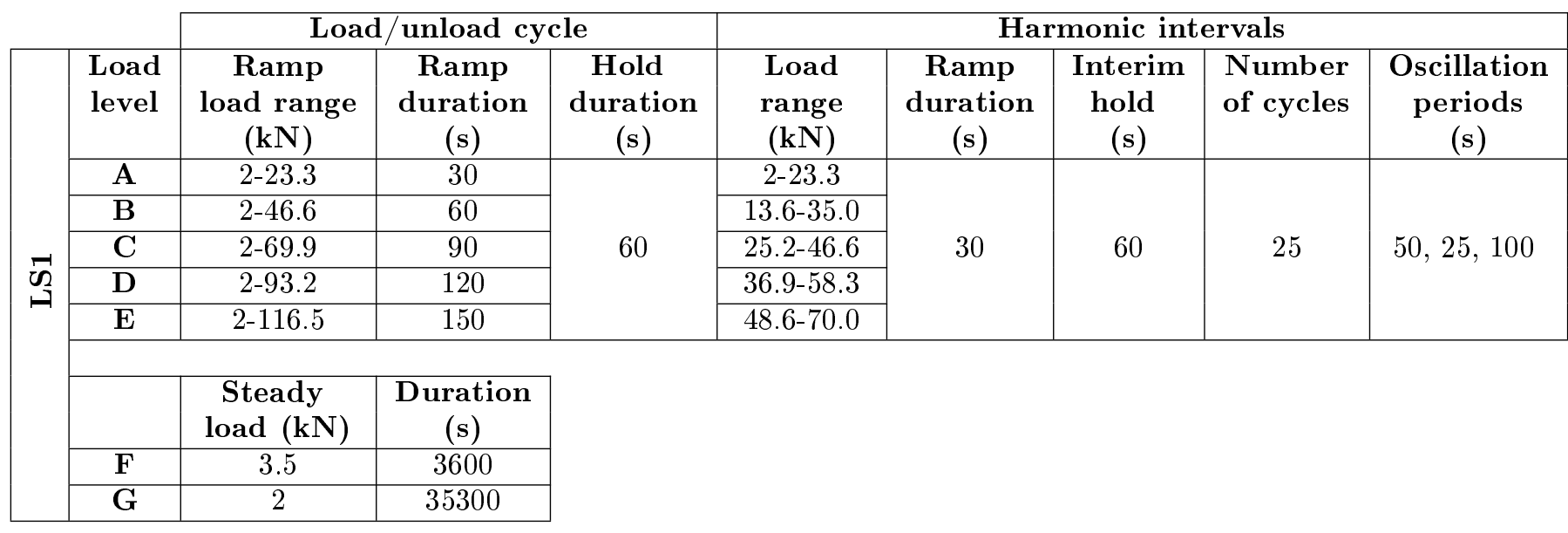

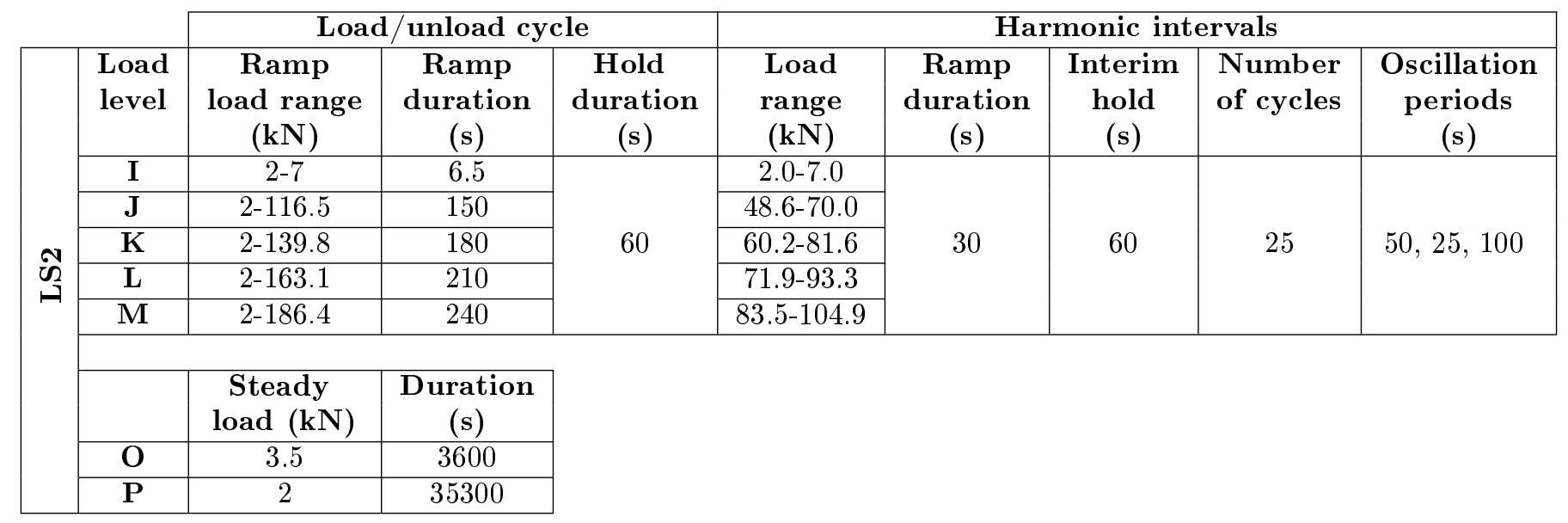

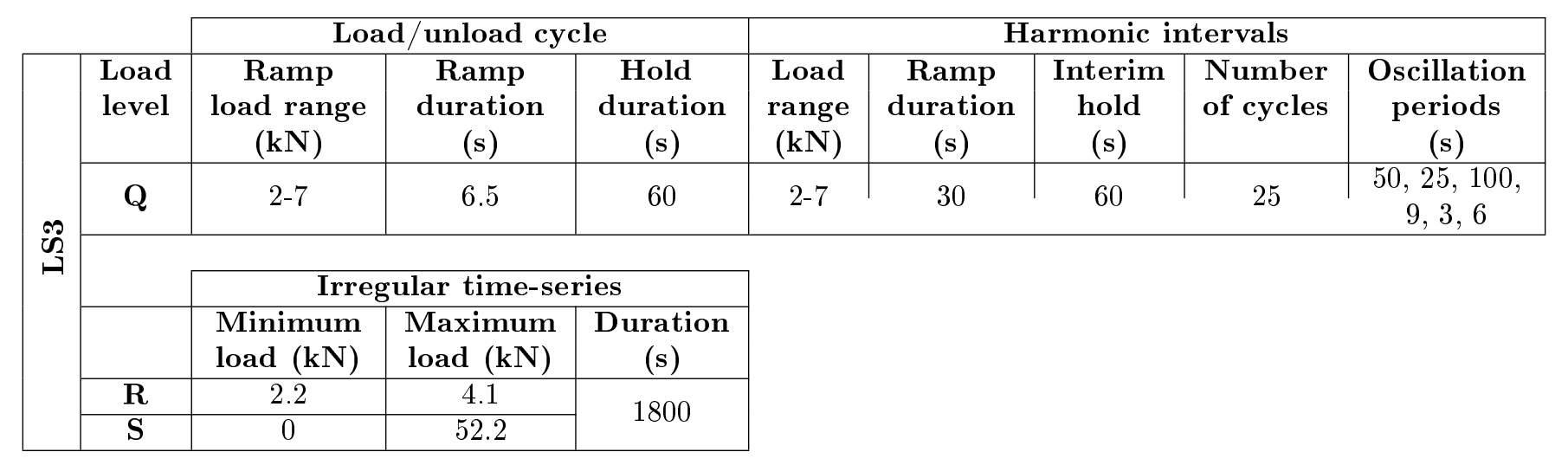

Table 3: Specified loading regimes 


\begin{tabular}{|c|c|c|c|c|c|}
\hline \multirow{2}{*}{ Method } & \multicolumn{5}{|c|}{ Cycle } \\
\cline { 2 - 6 } & $\mathbf{1}$ & $\mathbf{2}$ & $\mathbf{3}$ & $\mathbf{4}$ & $\mathbf{5}$ \\
\hline Single DoF trend line & $935.2(0.893)$ & $991.6(0.935)$ & $1009.0(0.938)$ & $1019.5(0.94)$ & $1030.4(0.941)$ \\
\hline Flory et al. ([10]) & $629.8(0.387)$ & $881.2(0.886)$ & $914.0(0.9)$ & $934.2(0.908)$ & $945.9(0.91)$ \\
\hline
\end{tabular}

\begin{tabular}{|c|c|c|c|c|c|}
\hline & $\mathbf{6}$ & $\mathbf{7}$ & $\mathbf{8}$ & $\mathbf{9}$ & $\mathbf{1 0}$ \\
\hline Single DoF trend line & $1036.8(0.942)$ & $1044.7(0.942)$ & $1048.9(0.943)$ & $1055.4(0.943)$ & $1057.8(0.944)$ \\
\hline Flory et al. ([10]) & $958.2(0.913)$ & $964.4(0.913)$ & $974.0(0.917)$ & $978.4(0.916)$ & $985.2(0.918)$ \\
\hline
\end{tabular}

Table 5: Comparison of axial stiffness values (units: $\mathrm{kN}$ ) calculated using two approaches, with coefficients of determination $R^{2}$ in parentheses

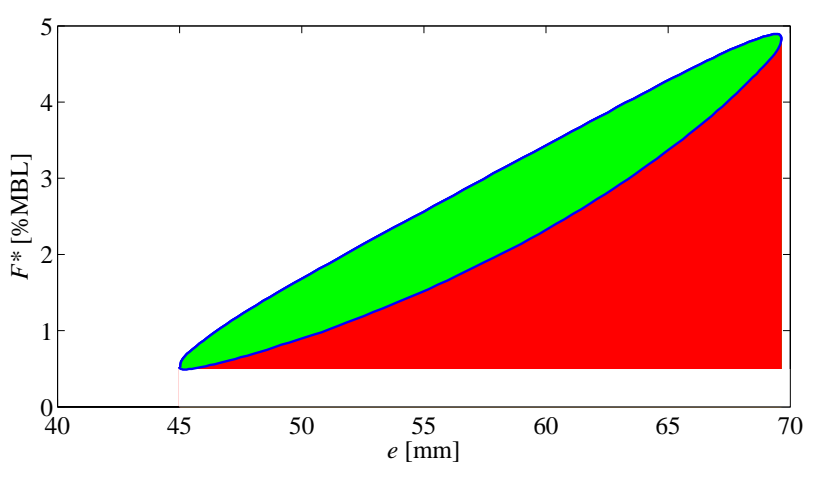

(a)

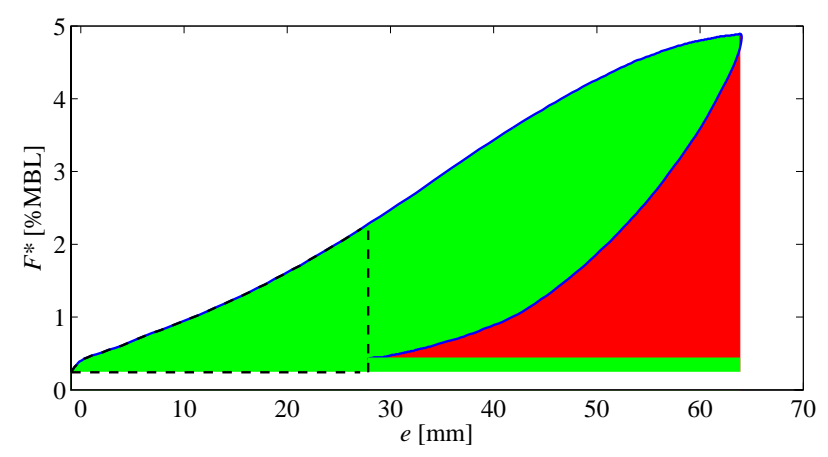

(b)

Figure 4: Examples of a) closed and b) open hysteresis loops for Sample 1 (blue line) showing energy during loading $\left(E_{\text {load }}\right.$; green region), energy during unloading ( $E_{\text {unload }}$; red region). In b) the energy associated with permanent or temporary extension $\left(E_{w d}\right)$ is defined as the area bounded by the dashed line. Measured loads are expressed as a percentage of the rope MBL $(F *=F / M B L)$. For interpretation of the references to colour in this figure legend, the reader is referred to the online version of the article.

The start and end of each oscillation cycle are defined by the calculated strain and extension $(e)$ minima, for axial stiffness and damping rate calculations respectively. For the bedding-in and harmonic loading regimes studied, both quantities are averaged over the last five oscillation cycles of each interval, whilst for the irregular loading regimes these values are calculated on a cycle-to-cycle basis. For fully closed hysteresis loops the energy dissipated can be approximated by finding the area enclosed within each extension-force loop using trapezoidal integration (Figure 4a):

$$
E_{d}=E_{\text {load }}-E_{\text {unload }}
$$

When temporary or permanent extension of the sample occurs due to constructional rearrangement and/or material changes, hysteresis loops are typically open (Figure $4 \mathrm{~b})$ and in this case the integration is bounded by the cycle start, end and maximum measured elongations $\left(e_{1}, e_{2}\right.$ and $\left.e_{\max }\right)$ as well as the start and end forces $\left(F_{e_{1}}\right.$ and $\left.F_{e_{2}}\right)$. For post-cycle extensions greater than $1 \mathrm{~mm}$ the energy associated with work done during loading $\left(E_{w d}\right)$ is calculated based on the area bounded by part of the loading curve and a single degree-of-freedom line fitted to the force and extension values at the beginning and end of each cycle:

$$
E_{w d}=\int_{e_{1}}^{e_{2}} F \mathrm{~d} e-F_{e_{1}}\left(e_{2}-e_{1}\right)
$$

For the loading regimes specified in this study $E_{w d}$ is notable for the load/unload cycles (e.g. $E_{w d}=0.16 E_{\text {load }}$, for the example shown in Figure $4 \mathrm{~b}$ ). Whilst some energy resulting from elongation is stored as strain energy, heat energy resulting from cyclic loading, displacement of structural elements or friction (between yarns, strands and fibres) will be dissipated from the system. In the closedsystem, adiabatic approximation used in this study heat energy transferred out of the system is not accounted for, but will be the subject of a future investigation.

\section{Harmonic Loading Performance}

In this section the average and time-varying performance of the three rope samples subjected to load sets LS1 and LS2 is reported, with relevant measurements contained within datasets, 'Inline Supplementary Sample1_LS1', 'Inline Supplementary Sample2_LS1', 'Inline Supplementary Sample3_LS1', 'Inline Supplementary Sample1_LS2', 'Inline Supplementary Sample2_LS2' and 'Inline Supplementary Sample3_LS2'. 


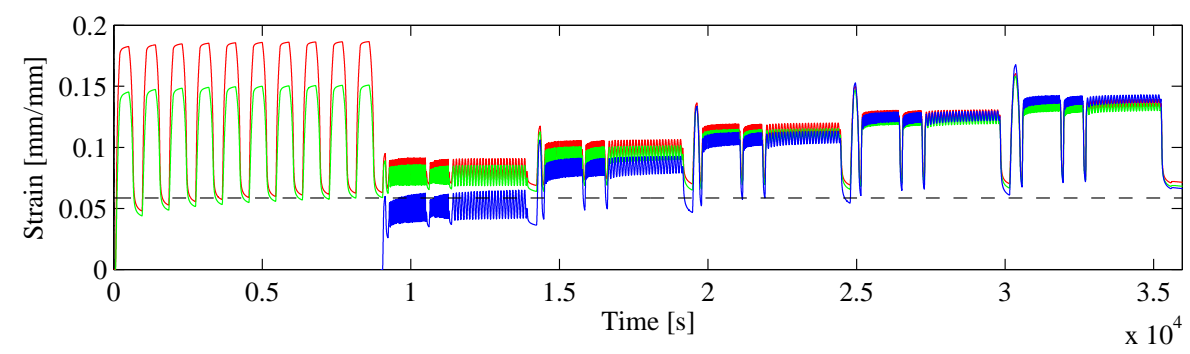

(a)

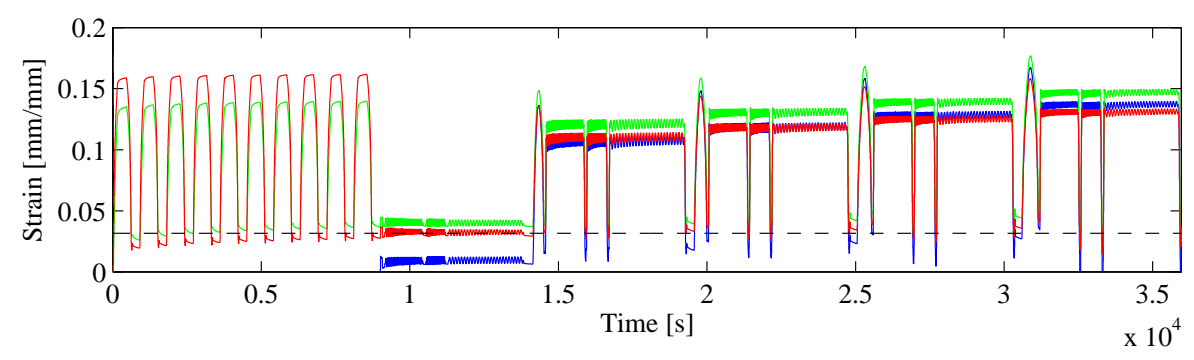

(b)

Figure 5: Calculated time-varying strain values for Sample 1 (blue line), Sample 2 (green line) and Sample 3 (red line) from measurements recorded during load levels a) A-E and b) I-M. For both load sets LS1 and LS2 the average strain of the three samples after 25.7 hours is shown as a black dash-dot line. For interpretation of the references to colour in this figure legend, the reader is referred to the online version of the article.

\subsection{Time-varying strain performance}

In Figure 5a calculated time-varying strain values are presented for the three different samples subjected to load levels A-E as part of load set LS1. The strain values for Sample 1 have been aligned by the minimum force measurement of the first load/unload cycle (at $t=9046 \mathrm{~s}$ ). There is a distinct difference in the evolution of strain for the three samples. Comparing the response of the bedded-in samples (2 and 3), the highest strains can be attributed to Sample 3 which was subjected to the highest bedding-in load level (BI3). Without bedding-in, the strain of Sample 1 is lower for the first three harmonic loading intervals and then highest for the last load level. Temporary material extension and rearrangement of the rope construction is suggested by the positive strain levels measured between each loading interval, during which there was insufficient time for significant strain recovery to occur. Notable recovery was recorded after 10.8 hours of steady loading, with residual strain levels of a similar magnitude to the final bedding-in cycles (5.5-6.3\%), suggesting permanent (or at least semi-permanent) extension. In Figure 5b time-varying strain values are presented for the three samples subjected to bedding-in (BI3) and load levels I-M. Although the sample strains measured at the end of load level $\mathrm{G}$ are known, the ropes were stored before the second round of tests (LS2) and unquantified sample relaxation is likely to have occurred during the interim period. Hence, strain values are based on the free length of each sample remeasured at a pretension of $2 \mathrm{kN}$. The strain values achieved during the BI3 bedding-in cycles demon- strate a similar trend to those measured during the BI2 bedding-in cycles, with the strain achieved after beddingin similar to the residual strain measured after steady load level $\mathrm{P}$ (between 2.3 and $3.9 \%$ ). In terms of the individual load/unload and harmonic cycles, the highest strains are attributed to the lowest bedding-in level (BI2) during load levels I-M.

\subsection{Axial stiffness and damping performance}

\subsubsection{Influence of mean load level}

Previous tests conducted by the authors on a section of aged rope of the same construction demonstrated that the application of higher mean load levels resulted in steeper hysteresis loops, leading to higher average axial stiffness values [20], reflecting studies conducted on HMPE and aramid ropes [6, 11]. For load sets LS1 and LS2 the same effect is demonstrated with the samples subjected to bedding-in cycles (Samples 2 and 3, subjected to BI2 and BI3 respectively) compared to Sample 1 (Figure 6a). Despite the scatter in the calculated axial stiffness and damping values for the individual load/unload cycles there is a general increase of both quantities with increasing mean load. It is interesting to note that the axial stiffness values calculated for the lower bedding-in level are marginally greater (by up to $5.3 \%$ ) than those for the higher beddingin level during harmonic load levels A-E. This contrasts the average stiffness values calculated for Samples 2 and 3 during harmonic load levels I-M, in which the higher stiffness values are attributable to Sample 3. Both effects appear to 

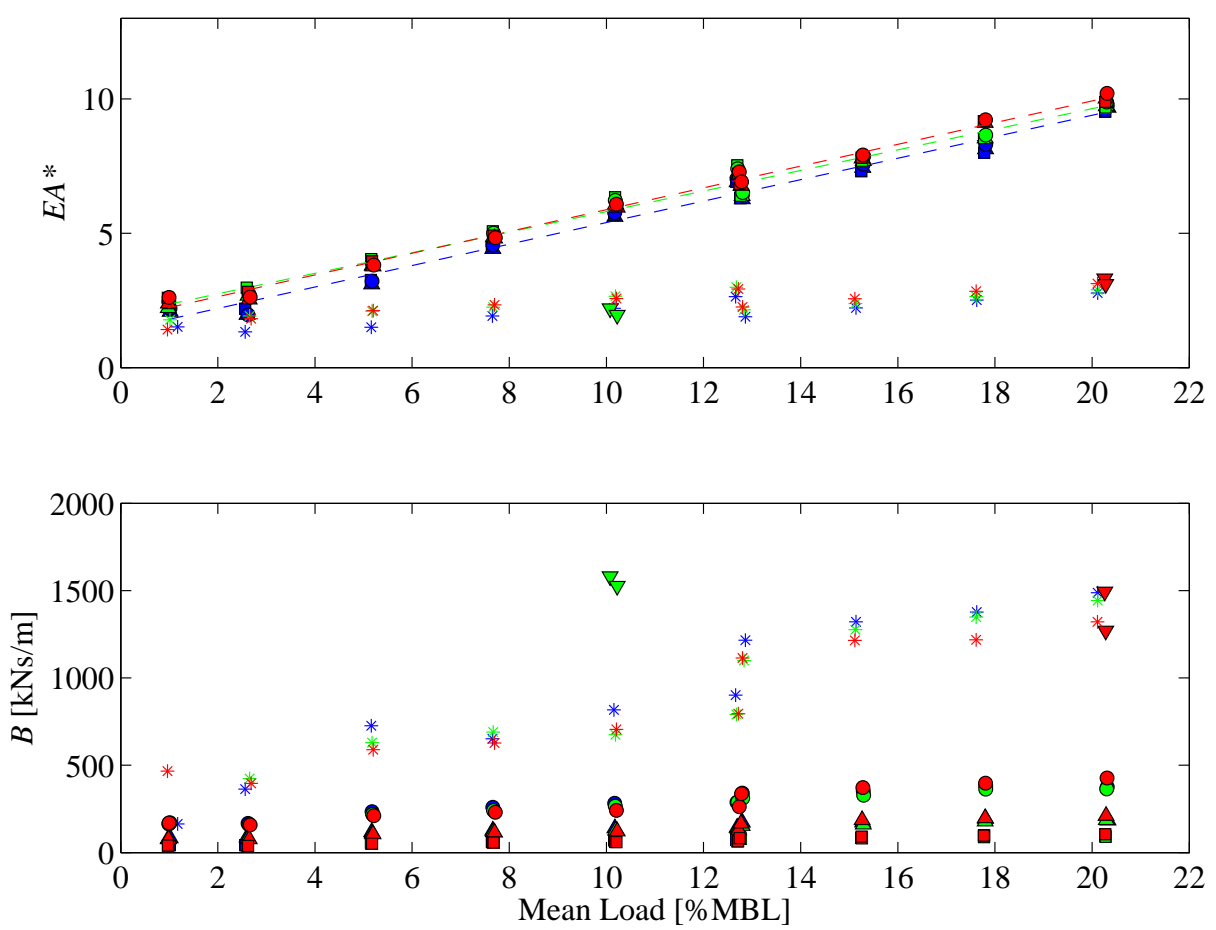

(a)
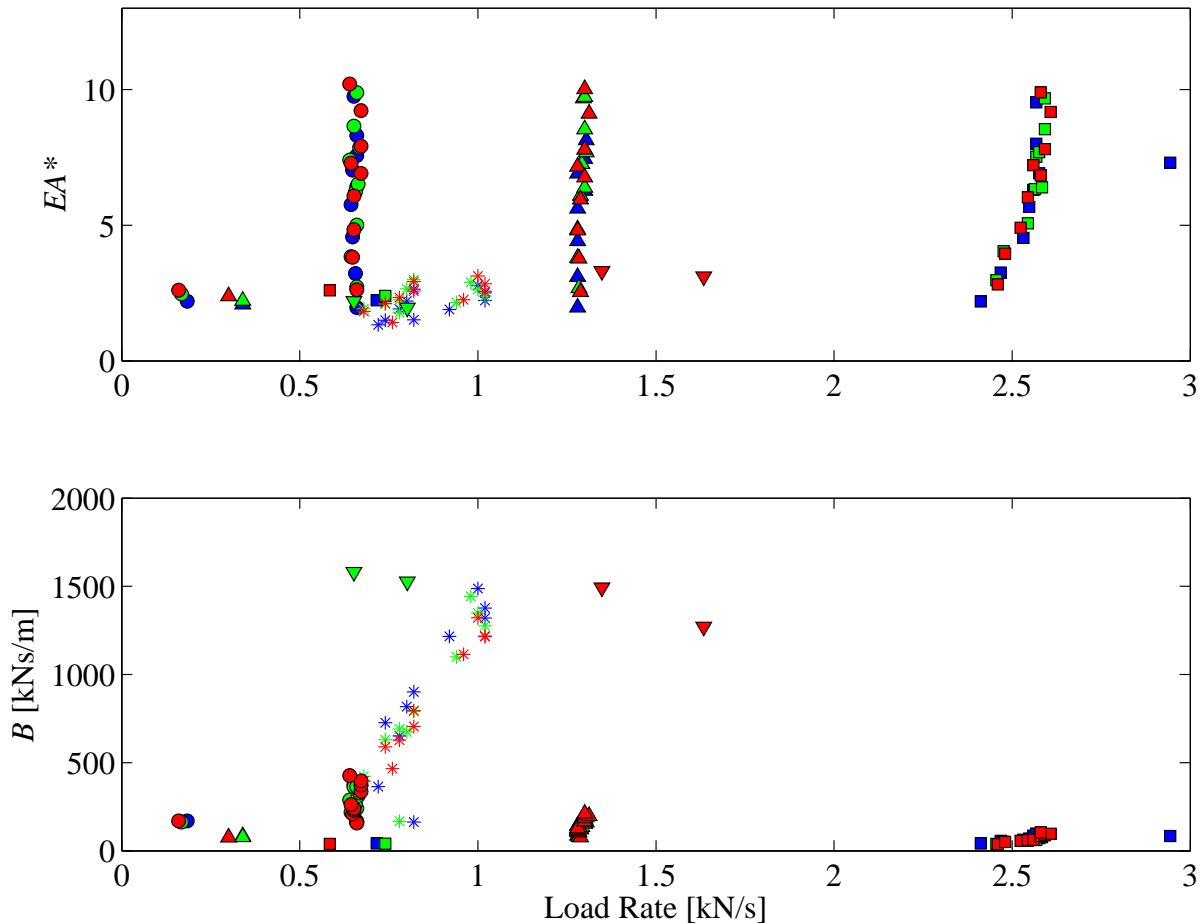

(b)

Figure 6: Variation of average (top) axial stiffness (normalised by the rope MBL; $E A *=E A / M B L$ ) and (bottom) damping values with a) mean load and b) maximum absolute load rate for load sets LS1 and LS2. Results are shown for Sample 1 (blue markers), Sample 2 (green markers) and Sample 3 (red markers) and for oscillation periods, 100s $(\bigcirc), 50 \mathrm{~s}(\triangle)$ and $25 \mathrm{~s}(\square)$, the initial load/unload cycle $(*)$ before each harmonic interval and (where relevant) the bedding-in cycles $(\nabla)$. For gach sample, a single degree-of-freedom trend line is fitted to harmonic values in (a). For interpretation of the references to colour in this figure legend, the reader is referred to the online version of the article. 


\begin{tabular}{|c|c|c|c|c|}
\cline { 2 - 4 } \multicolumn{1}{c|}{} & \multicolumn{3}{c|}{ nylon samples } & \multirow{2}{*}{ polyester [11] } \\
\cline { 2 - 4 } \multicolumn{1}{c|}{$\mathbf{1}$} & $\mathbf{2}$ & $\mathbf{3}$ & \\
\hline$m$ & 0.4 & 0.38 & 0.4 & 0.33 \\
\hline$c$ & 1.4 & 1.96 & 1.83 & 18.5 \\
\hline
\end{tabular}

Table 6: Calculated gradient $(m)$ and $y$-intercept $(c)$ values for the three nylon samples and polyester

be related to the dynamic stiffness of the samples during the unloading stage of the final bedding-in cycle and the final strain achieved. Referring to Figure 5a, the strain at the end of bedding-in for Sample 3 is $6.7 \%$ higher than Sample 2 during load set LS1, with a shallower unloading path (Figure 7a) and subsequently lower average stiffness values during harmonic loading. Conversely for the second load set (LS2) the strain for Sample 2 is $25 \%$ higher than Sample 3 (Figure 5b) and it is Sample 2 that demonstrates a shallower unloading path (Figure $7 \mathrm{~b}$ ), with lower average stiffness values during harmonic loading. Repetition of the bedding-in cycles results in a notable drop in average stiffness (by $11 \%$ for Sample 2 and $6.1 \%$ for Sample 3 ) and this behaviour is also demonstrated for the common load levels $\mathrm{E}$ and J. A single degree-of-freedom trend line fitted to mean load $\left(F_{\text {mean }}\right)$ and axial stiffness values (both normalised by the rope MBL) can be used to determine the 'Krebi', or dynamic stiffness of a rope sample [3]. Krebi values are defined in terms of trend line gradient $(m)$ and $y$-intercept $(c)$ values: $K r D=m\left(\frac{F_{\text {mean }}}{M B L}\right) * 100+c$ in Table 6 for load sets LS1 and LS2. For comparative purposes Krebi gradient and $y$-intercept values for a parallel-strand polyester rope (800 Tonne MBL) as reported by François et al. in [11] are also listed. Despite differences in the loading regimes applied (i.e. in [11] 100 cycles with higher mean loads ranging from approximately 6-50\% MBL and various amplitude ranges were used), gradient $(m)$ values observed in the current study suggest broadly similar behaviour for nylon at lower mean loads.

\subsubsection{Influence of load rate}

It was also shown in [20] that there was an effect of harmonic oscillation period (and hence load rate) on both average axial stiffness and damping. The axial stiffness values calculated for the bedding-in cycles contained within load sets LS1 and LS2 are in agreement with this, in that the lower axial stiffness values correspond to bedding-in cycles with lower load rates (Figure $6 \mathrm{~b}$ ). The same inverse relationship between harmonic damping and load rate also exists for the new rope samples. However, unlike the previous study, the trend between load rate and axial stiffness is non-monotonic for the harmonic loading intervals. Whilst the same load levels were applied, the previous study differed in two respects: i) a larger range of monotonically ordered oscillation periods were used (100, 50, 25, 9, 6 and $3 \mathrm{~s}$ ), and ii) each interval was conducted as a separate test. It is likely that sample recovery occurred between each in- terval. For the range of oscillation periods utilised in load sets LS1 and LS2 the influence of load rate on axial stiffness appears to be small.

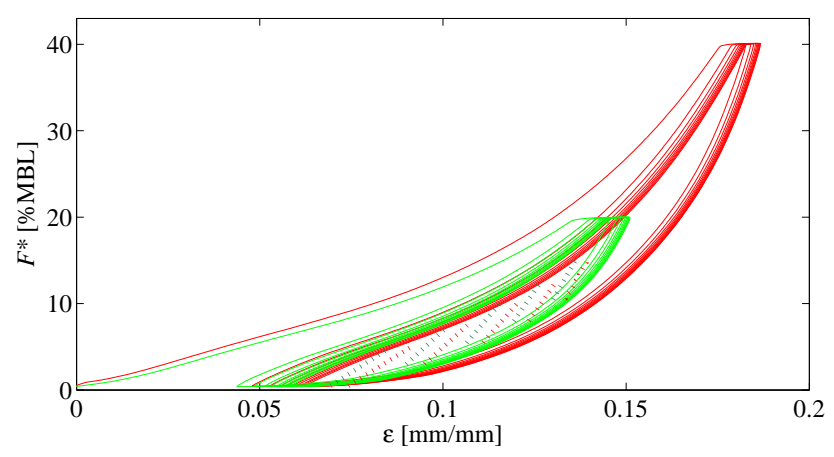

(a)

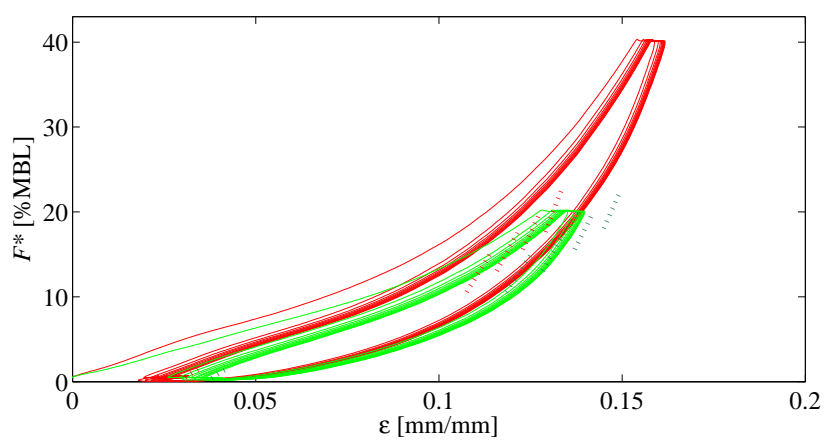

(b)

Figure 7: Bedding-in hysteresis loops for Samples 2 (BI2; green line) and 3 (BI3; red line) for load sets a) LS1 and b) LS2. Fitted single degree-of-freedom trend lines for the last cycle of each 100s harmonic interval are also shown (dark green and dark red dashed lines). Measured loads are expressed as a percentage of the rope MBL $(F *=F / M B L)$. For interpretation of the references to colour in this figure legend, the reader is referred to the online version of the article.

\subsubsection{Cycle-to-cycle analysis}

Analysis of the measurement data on a cycle-to-cycle basis reveals the influence of load history on the immediate strain, axial stiffness and damping properties of the rope. For both load sets LS1 and LS2 the axial stiffness of rope Samples 2 and 3 reach a fairly steady state during the bedding-in cycles (Figures 8 and 9). In this figure, negative damping values which correspond to sample recovery in the short interval between harmonic cycling (when $E_{\text {load }}<E_{\text {unload }}$ ) are not presented. The application of progressively higher mean loads leads to a continued increase in axial stiffness, which is also observed during each harmonic interval. Both axial stiffness and damping start to become steady after 25 cycles and it is expected that steady-state behaviour would be achieved after fur- 

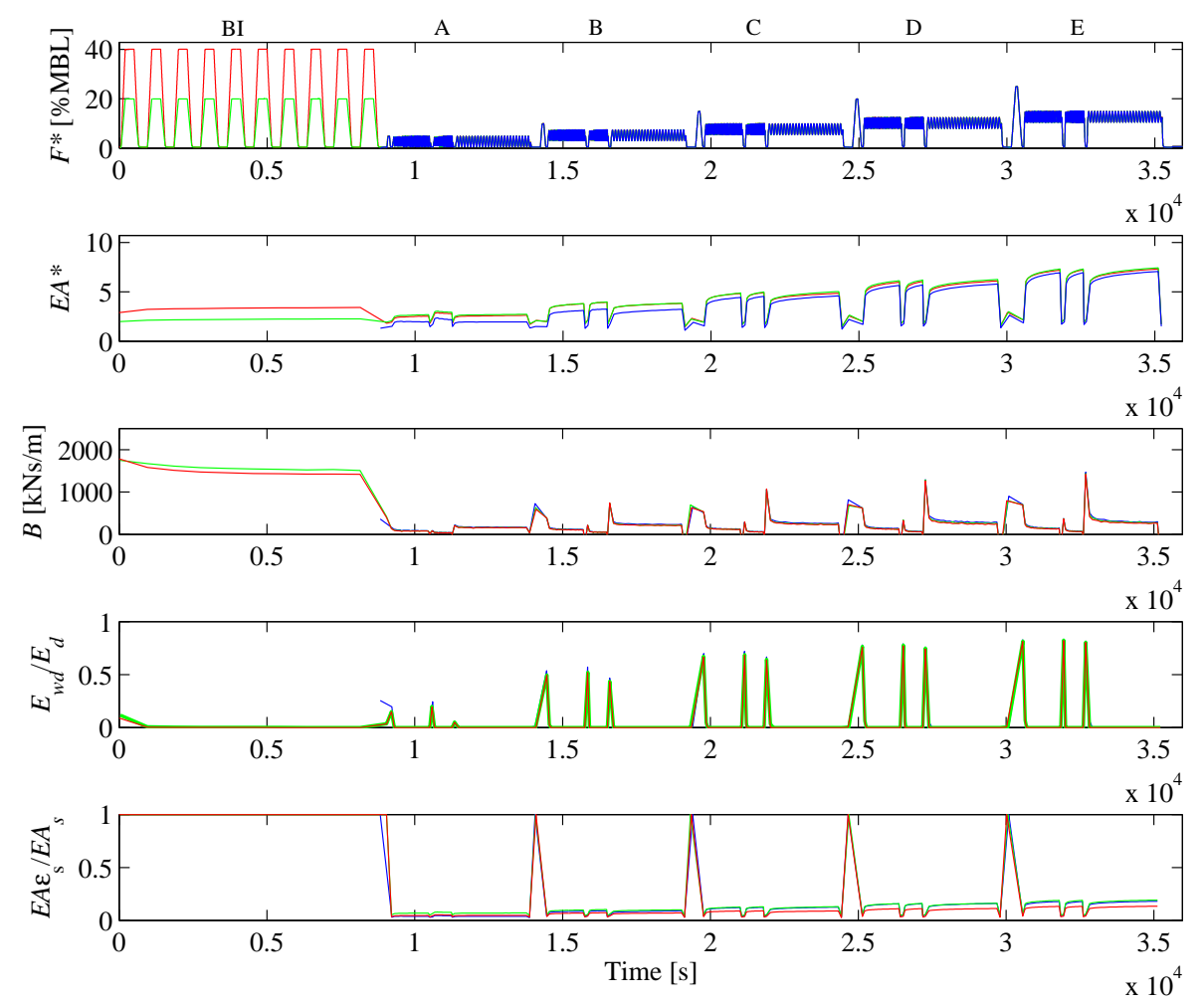

Figure 8: Cycle-by-cycle calculated normalised axial stiffness $(E A *)$, damping $(B)$, non-dimensionalised work done-dissipated energy ratio $\left(E_{w d} / E_{d}\right)$ and axial stiffness-strain ratio $\left(E A \epsilon_{s} / E A_{s}\right)$ for Sample 1 (blue line), Sample 2 (green line) and Sample 3 (red line) subjected to bedding-in (where relevant) and load levels A-E (from LS1). Negative damping values which correspond to extension-load loops which include sample recovery between harmonic intervals are not shown. For reference the load time-series applied to each sample are also shown as a percentage of the rope $\mathrm{MBL}(F *=F / M B L)$. For interpretation of the references to colour in this figure legend, the reader is referred to the online version of the article.

ther load cycling. The stabilisation of both quantities corresponds with a decrease in energy expended to temporary or permanent extension of the sample (this quantity has been normalised by the dissipated energy; $E_{w d} / E_{d}$ in Figures 8 and 9). In Section 3.2.1 it was shown that the average properties of the rope following bedding-in are related to the final strain and unloading stiffness of the last bedding-in cycle. This approach is extended by applying the calculated final strain and axial stiffness values of each load/unload cycle (denoted $\epsilon_{s}$ and $E A_{s}$ respectively) to the axial stiffness of each cycle for each load level. For both load sets the resulting ratios $\left(E A \epsilon_{s} / E A_{s}\right)$ are relatively constant with time, illustrating that both the immediate strain and the axial stiffness for a particular load level will influence subsequent levels of stiffness.

\section{Harmonic/Irregular Loading Performance}

In this section the performance of the new rope samples subjected to load set LS3 is investigated, with rele- vant measurements contained within datasets 'Inline Supplementary Sample1_LS3', 'Inline Supplementary Sample2_LS3' and 'Inline Supplementary Sample3_LS3'. Using the DMaC test facility the samples were subjected to load set LS3, comprising low load harmonic cycling (load level Q), followed by two 30 minute representations of tensions measured in calm and mild-storm conditions (load levels $\mathrm{R}$ and $\mathrm{S}$ respectively) by one mooring line of the SWMTF (denoted 'Line 1' in Figure 2a). For these intervals a cubic spline was fitted to the time-series to provide a smooth command input to the $\mathrm{DMaC}$ without compromising on input signal amplitude or phase. Calculated time-varying strain values for the three rope samples are presented in Figure 10 for load set LS3. If the average axial stiffness and damping values calculated from load level $\mathrm{Q}$ are compared to I (for common oscillation periods 25100s) damping values for load set LS3 are generally higher (Table 7). As with the previous load sets, a monotonic increase in axial stiffness is observed for oscillation periods $T \leq 50 \mathrm{~s}$ and a decreasing trend of damping values with oscillation period is noted. In the absence of bedding-in 

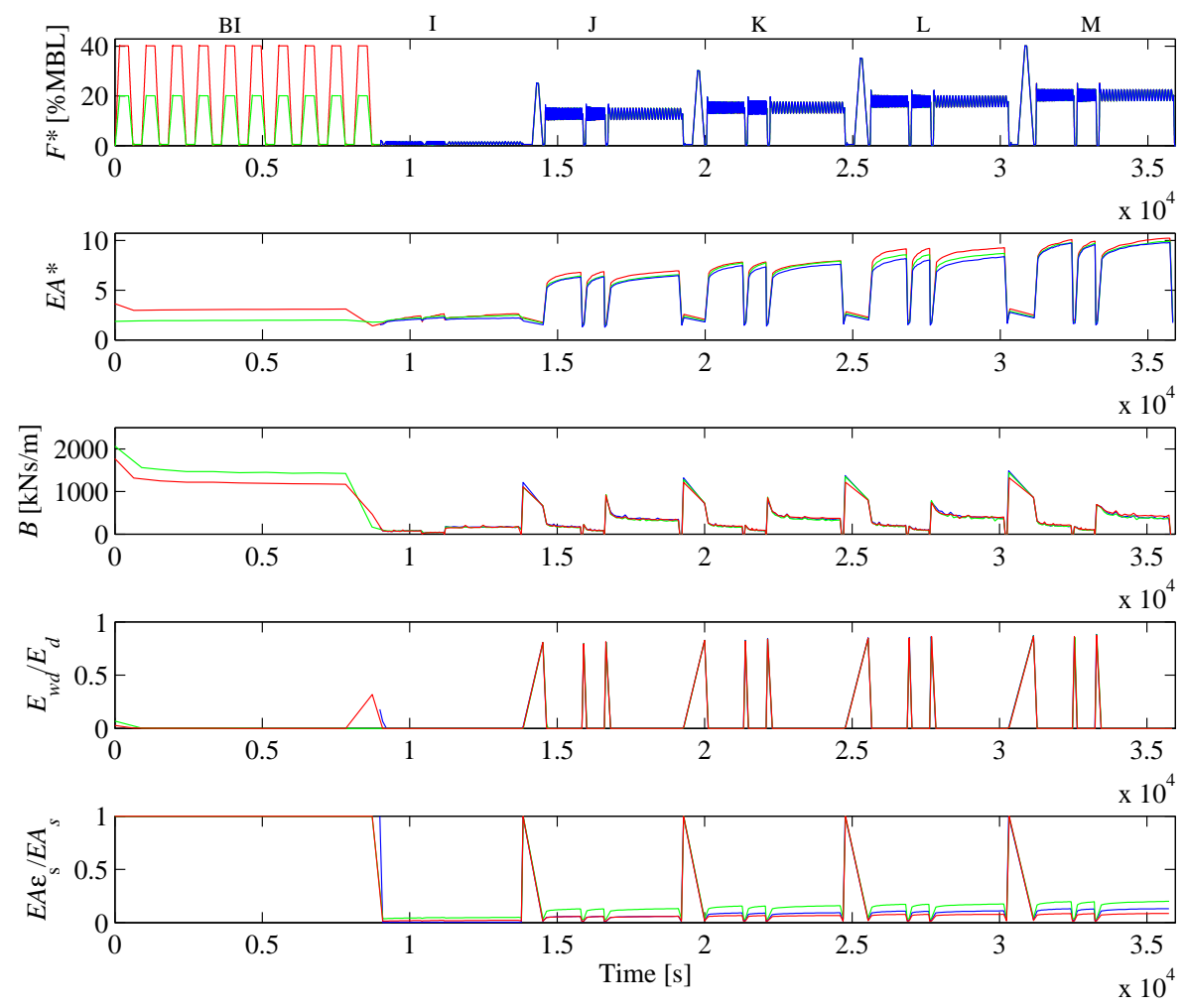

Figure 9: As Figure 8 for load levels I-M (from LS2)

cycles during LS3, Samples 2 and 3 exhibit similar levels of strain to Sample 1 and it is likely that partial recovery and rearrangement of all three samples occurred during storage and handling. The lower level of strain achieved by Samples 2 and 3 during LS3 compared to LS2 is also reflected in lower axial stiffness values, illustrating the reliance of rope properties on time-variant processes such as strain.

Applying the same measurement analysis procedure outlined in Section 2.4 the cycle-by-cycle properties of the samples subjected to LS3 are presented in Figure 11. For the irregular load intervals $\mathrm{R}$ and $\mathrm{S}$, the angular frequency term used in Equation 1 to calculate damping is based on the measured time difference between piston displacement minima. This effectively assumes that each irregular cycle can be represented as an isolated harmonic cycle and whilst most cycles are not regular in profile, this approach serves as a first approximation to the damping occurring during irregular loading and provides an alternative to load spectral analysis. The negative damping values displayed correspond to hysteresis loops where the level of energy during the unloading interval is much greater than during the loading interval and are indicative of energy flows into and out of the system.
Comparison of the harmonic and irregular performance of the rope during load set LS3 reveals several interesting characteristics. Whilst the mean load and load rates for the analysed cycles within the calm irregular interval are similar to the $T=3$ s and $T=6$ s harmonic intervals, the notably large stiffness values calculated can be attributed to cycle load amplitudes less than $0.8 \mathrm{kN}$ (e.g. Figure $12 \mathrm{a}$ for Sample 1). The increase in axial stiffness with decreasing load amplitude was demonstrated for various synthetic materials by François et al. in [11]. It can be seen in Figure $12 \mathrm{a}-\mathrm{c}$ that average axial stiffness and damping values for oscillation periods $3-9 \mathrm{~s}$ (filled diamond markers) are comparable to values from the mild-storm time-series for corresponding mean loads, load amplitudes and maximum absolute load rates. This analysis illustrates that average values based on harmonic loading may provide indicative values for rope axial stiffness and damping if similar oscillation periods are utilised. However, this approach cannot account for temporal material property and construction changes (in particular strain level) resulting from highly irregular loading regimes which comprise many cycles of varying load amplitude, mean load and load rate. 


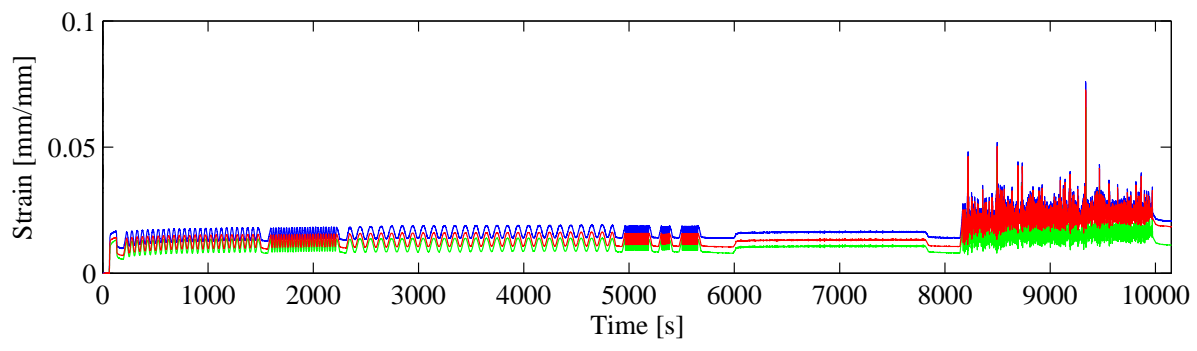

Figure 10: Calculated time-varying strain values for Sample 1 (blue line), Sample 2 (green line) and Sample 3 (red line) subjected to a mixed harmonic and irregular load time-series. For interpretation of the references to colour in this figure legend, the reader is referred to the online version of the article.

\begin{tabular}{|c|c|c|c|c|c|c|c|c|}
\hline & \multicolumn{6}{|c|}{ Sample } \\
\hline & & & \multicolumn{2}{|c|}{1} & \multicolumn{2}{|c|}{2} & \multicolumn{2}{|c|}{3} \\
\hline & & & $E A(\mathrm{kN})$ & $B(\mathrm{kNs} / \mathrm{m})$ & $E A(\mathrm{kN})$ & $B(\mathrm{kNs} / \mathrm{m})$ & $E A(\mathrm{kN})$ & $B(\mathrm{kNs} / \mathrm{m})$ \\
\hline \multirow{6}{*}{ 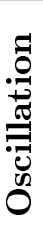 } & \multirow{6}{*}{ 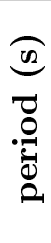 } & 50 & $1016.6(970.4)$ & $112.9(83.2)$ & $947.7(1033.4)$ & $103.0(79.2)$ & $935.0(1112.1)$ & $85.4(76.9)$ \\
\hline & & 25 & $1099.4(1042.0)$ & $61.0(41.7)$ & $1029.4(1115.9)$ & $52.8(40.2)$ & $999.1(1209.8)$ & $42.1(39.5)$ \\
\hline & & 100 & $1031.3(1023.9)$ & $217.3(170.0)$ & $966.3(1147.2)$ & $211.0(163.5)$ & $934.3(1215.9)$ & $162.8(169.6)$ \\
\hline & & 9 & 1184.7 & 20.6 & 1135.1 & 19.7 & 1090.1 & 16.0 \\
\hline & & 3 & 1346.2 & 7.2 & 1224.6 & 6.7 & 1205.4 & 5.6 \\
\hline & & 6 & 1255.7 & 14.4 & 1169.9 & 12.7 & 1122.0 & 10.6 \\
\hline
\end{tabular}

Table 7: Average axial stiffness and damping for the three rope samples subjected to low load harmonic loading (load level Q). Comparable results from load set LS2 (load level I) are listed in brackets

\section{Conclusions}

It has been the purpose of this study to quantify the time-averaged and time-varying axial stiffness properties of a commercially available nylon mooring rope. Three rope samples of the same parallel-stranded construction have been subjected to mean loads and load rates that are relevant to buoy-like MRE devices and small offshore equipment deployed in highly dynamic environments. To the knowledge of the authors, it is the first time that damping properties have been quantified and time-series datasets provided for the purpose of numerical model development. By utilising different levels of bedding-in prior to applying a common load profile to each sample (comprising a mixture of load/unload, harmonic and steady load intervals), the influence of load history on rope conditioning has been investigated on a time-varying and timeaveraged basis. The measurements presented in this study indicate that the use of bedding-in cycles has a significant influence on the performance of the rope due to the different levels of strain achieved prior to harmonic loading. This has been demonstrated by the progressive application of load sets (LS1 followed by LS2) comprising identical bedding-in cycles. It can be concluded that the choice of bedding-in level specified for nylon mooring lines prior to the installation of a MRE device will therefore influence the short-term performance of the mooring system. The incorrect specification of bedding-in level may necessitate re-tensioning of the mooring lines if bedding-in is not achieved via the mooring loads experienced in ser- vice (i.e. due to device motions and environmental loading). The axial stiffness and damping of the rope samples studied are both dependent on both the mean load level applied, with a substantial increase of axial stiffness with mean load (from 934.3-4754kN for the range of harmonic loads tested), reflecting previous studies with other mooring rope materials, including polyester. Whilst there is an inverse relationship between hysteresis damping and harmonic oscillation period, the trend between sample stiffness and harmonic oscillation period is non-monotonic for oscillation periods greater than $25 \mathrm{~s}$. Calculation of these quantities on a cycle-to-cycle basis demonstrates that the previous load history will directly affect the instantaneous stiffness and damping of the line due to the level of strain achieved by the rope. Sequential performance effects are particularly clear from measurements recorded during irregular loading. Whilst the calculated axial stiffness and damping values for the mild-storm irregular time-series (based on SWMTF measured tensions) are broadly similar to those calculated for harmonic load cycling at similar mean load levels, amplitudes and load rates a clear correlation of axial stiffness or damping with each of these load parameters is not observed. Instead, the results suggest that rope performance is greatly influenced by the instantaneous strain of the sample which brings into question the suitability of applying existing rope testing techniques comprising many hundreds (or even thousands) of load cycles. Whilst the standardised approach can provide an indicative measure of line performance for mooring systems subjected to low frequency load oscillations 


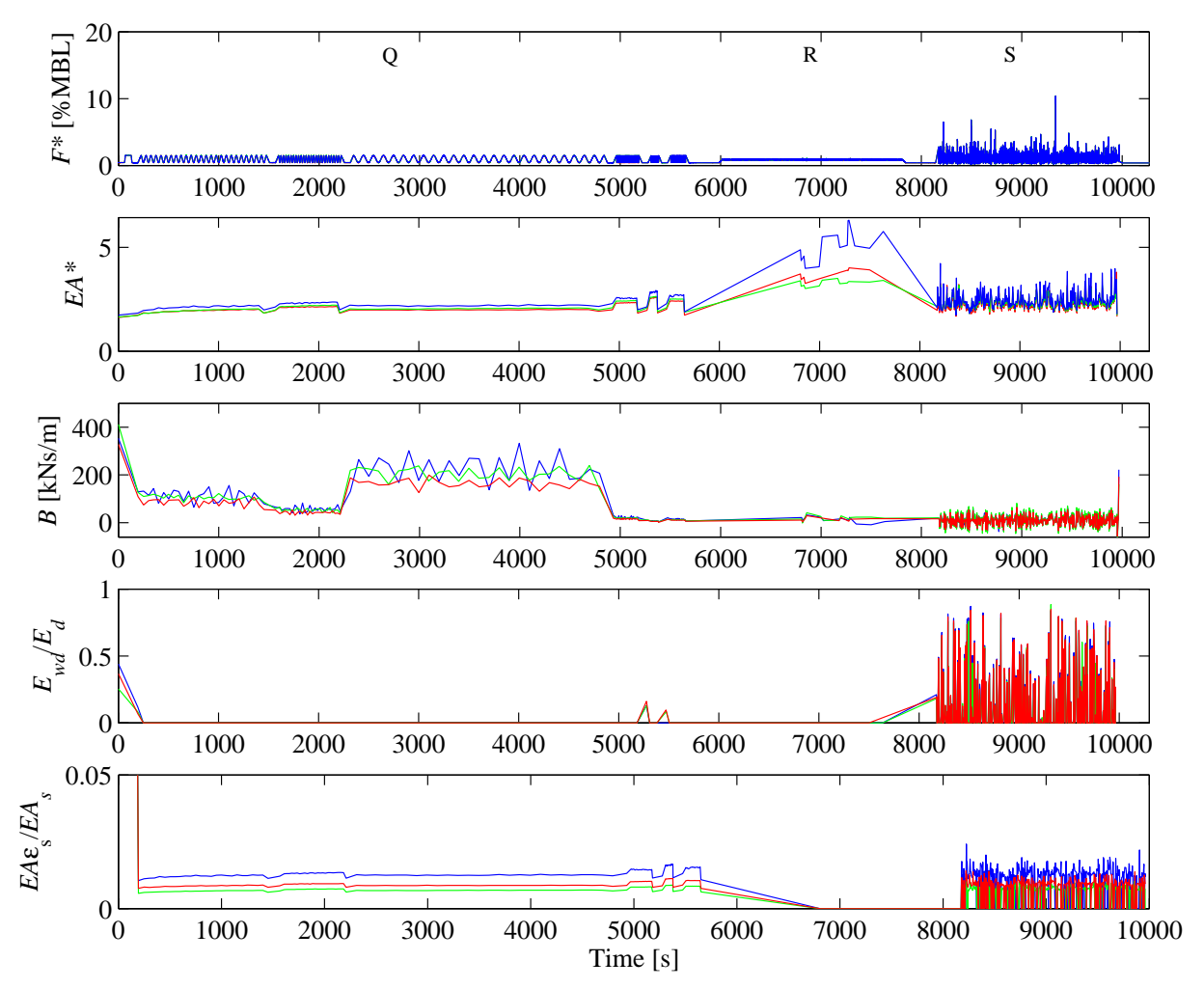

Figure 11: As Figure 8 for load levels Q-S (from LS3). Line-styles are defined in Figure 8 and cycles with load ranges less than 1.0kN are also not displayed. For interpretation of the references to colour in this figure legend, the reader is referred to the online version of the article.

(i.e. resulting from the slow drift motions of large equipment), this study has shown that the use of representative loading regimes including in-service measurements is more suitable for smaller, more responsive offshore equipment deployed in highly dynamic environments. It is proposed that the long-term monitoring of mooring line tensions by a MRE device or unique facility such as the SWMTF will enable laboratory load time-series to be compiled based on integrated wave-motion-load spectra. Insight into the evolution of synthetic component performance over time due to load history and fatigue mechanisms is essential to carry out lifecycle analysis and maintenance scheduling of offshore equipment. This study has focused on the short-term variation of nylon rope properties. The effect of sample conditioning (including water absorption) on rope performance will be investigated in a forthcoming publication. Comparisons will also be made to the behaviour of an aged rope sample used during the first deployment of the SWMTF.

\section{Acknowledgments}

The authors would like to acknowledge the support of the MERiFIC project partners. The project is funded by the European Regional Development Fund through the Interreg IV-A programme. Through the Peninsula Research Institute for Marine Renewable Energy (PRIMaRE) consortium, the DMaC test facility and SWMTF were funded from the ERDF Convergence programme and South West Regional Development Agency.

[1] American Bureau of Shipping, 2011. Guidance Notes on the Application of Fiber Rope for Offshore Mooring.

[2] Banfield, S., Veravel, T., Snell, R.O., Ahilan, R.V., 2000. Fatigue Curves for Polyester Moorings - A State-of-the-Art Review, in: 2000 Offshore Technology Conference (OTC12175), Houston, USA.

[3] Bureau Veritas, 2007. Certification of Fibre Ropes for Deepwater Offshore Services. Guidance note: NI 432 DTO R01E. Bureau Veritas, Paris, France.

[4] Chailleux, E., Davies, P., 2003. Modelling the Non-Linear Viscoelastic and Viscoplastic Behaviour of Aramid Fibre Yarns. Mechanics of Time-Dependent Materials 7, 291-303.

[5] da Costas Mattos, H.S., Chimisso, F.E.G., 2011. Modelling creep tests in HMPE fibres used in ultra-deep-sea mooring ropes. International Journal of Solids and Structures 48, 144152.

[6] Davies, P., Reaud, Y., Dussud, L., Woerther, P., 2011. Mechanical behaviour of HMPE and aramid fibre ropes for deep sea handling operations. Ocean Engineering 38, 2208-2214.

[7] Det Norske Veritas, 2010. Offshore standard - position mooring. DNV-OS-E301.

[8] Fitzgerald, J., Bergdahl, L., 2008. Including moorings in the 

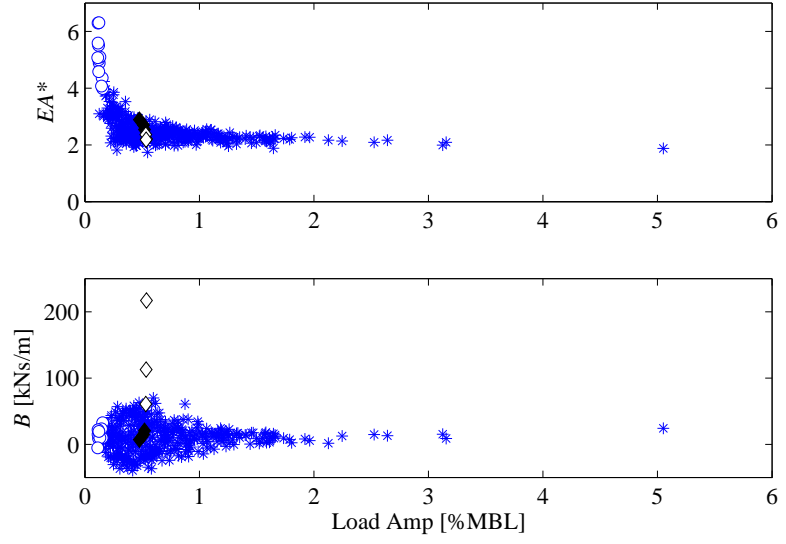

(a)
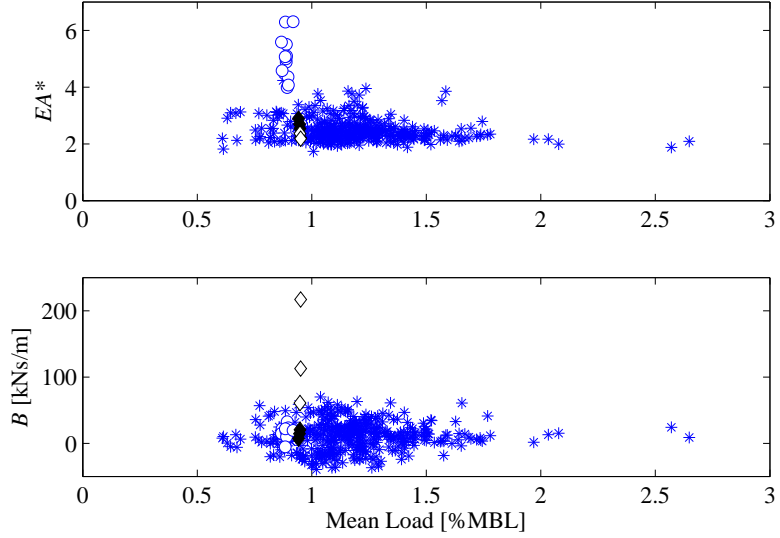

(b)
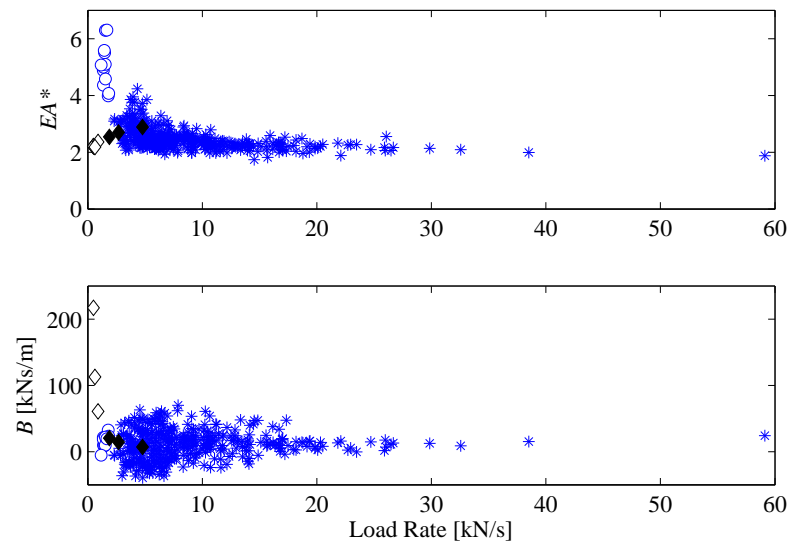

(c)

Figure 12: Per-cycle (top) axial stiffness and (bottom) damping rate values with a) load amplitude, b) mean load and c) maximum absolute load rate for Sample 1 subjected to the calm $(\bigcirc)$ and mild-storm sea-states (blue asterisks; *). Calculated average harmonic values $(\bullet)$ for oscillation periods 25-100s and 3-9s are shown as unfilled and filled black markers respectively. For interpretation of the references to colour in this figure legend, the reader is referred to the online version of the article.

assessment of a generic offshore wave energy converter: A frequency domain approach. Marine Structures 21, 23-46.

[9] Flory, J.F., Banfield, S.P., Petruska, D.J., 2004. Defining, Measuring, and Calculating the Properties of Fiber Rope Deepwater Mooring Lines, in: Proceedings of the Offshore Technology Conference (OTC 16151), Houston, USA.

[10] Flory, J.F., Leech, C.M., Banfield, S.P., Petruska, D.J., 2005. Computer Model to Predict Long-Term Performance of Fiber Rope Mooring Lines, in: Proceedings of the 2005 Offshore Technology Conference (OTC 17592), Houston, USA.

[11] François, M., Davies, P., Grosjean, F., Legerstee, F., 2010. Modelling of fibre rope load-elongation properties - Polyester and other fibres, in: Proceedings of the 2010 Offshore Technology Conference (OTC 20846), Houston, USA.

[12] IEC, 2013. Marine energy - Wave, tidal and other water current converters - Part 10: The assessment of mooring system for marine energy converters. IEC-TS 62600-10 Ed.1.0 (In-Progress).

[13] International Standards Organisation, 2007. Fibre ropes for offshore station keeping - Polyester. ISO 18692.

[14] Johanning, L., Smith, G.H., Wolfram, J., 2006. Mooring design approach for Wave Energy Converter. Journal of Eng. for the Maritime Env. (JEME) 220, 159-174.

[15] Johanning, L., Smith, G.H., Wolfram, J., 2007. Measurements of static and dynamic mooring line damping and their importance for floating WEC devices. Ocean Engineering 34, 19181934.

[16] Johanning, L., Thies, P.R., Parish, D., Smith, G.H., 2011. Offshore reliability approach for floating renewable energy devices, in: Proceedings of the 30th International Conference on Ocean, Offshore and Arctic Engineering, Rotterdam, Netherlands.

[17] McKenna, H.A., Hearle, J.W.S., O'Hear, N., 2004. Handbook of fibre rope technology. Woodhead Publishing Limited, Cambridge, UK.

[18] Ridge, I.M.L., Banfield, S.J., Mackay, J., 2010. Nylon Fibre Rope Moorings for Wave Energy Converters, in: Proceedings of the OCEANS 2010 conference, Seattle, USA.

[19] The Carbon Trust, 2005. Guidelines on design and operation of wave energy converters.

[20] Thies, P.R., Johanning, L., Gordelier, T., Vickers, A., Weller, S., 2013. Physical component testing to simulate dynamic marine load conditions, in: Proceedings of the 32nd International Conference on Ocean, Offshore and Arctic Engineering, Nantes, France.

[21] Weller, S., Davies, P., Thies, P.R., Harnois, V., Johanning, L., 2012. Durability of synthetic mooring lines for ocean energy devices, in: Proceedings of the 4th International Conference on 
Ocean Energy, Dublin, Ireland. 